\title{
Proteasome inhibitor bortezomib modulates TLR4-induced dendritic cell activation
}

Alessio Nencioni, Karin Schwarzenberg, Katharina M. Brauer, Susanne M. Schmidt, Alberto Ballestrero, Frank Grünebach and Peter Brossart

\footnotetext{
Updated information and services can be found at: http://bloodjournal.hematologylibrary.org/content/108/2/551.full.html

Articles on similar topics can be found in the following Blood collections Chemokines, Cytokines, and Interleukins (564 articles)

Immunobiology (4744 articles)
}

Information about reproducing this article in parts or in its entirety may be found online at: http://bloodjournal.hematologylibrary.org/site/misc/rights.xhtml\#repub_requests

Information about ordering reprints may be found online at:

http://bloodjournal.hematologylibrary.org/site/misc/rights.xhtml\#reprints

Information about subscriptions and ASH membership may be found online at: http://bloodjournal.hematologylibrary.org/site/subscriptions/index.xhtml

Blood (print ISSN 0006-4971, online ISSN 1528-0020), is published weekly by the American Society of Hematology, 2021 L St, NW, Suite 900, Washington DC 20036.

Copyright 2011 by The American Society of Hematology; all rights reserved.

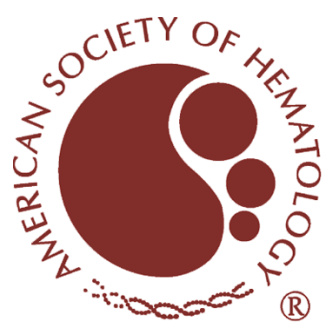




\title{
Proteasome inhibitor bortezomib modulates TLR4-induced dendritic cell activation
}

\author{
Alessio Nencioni, Karin Schwarzenberg, Katharina M. Brauer, Susanne M. Schmidt, Alberto Ballestrero, \\ Frank Grünebach, and Peter Brossart
}

\begin{abstract}
Evidence from the animal model suggests that proteasome inhibitors may have immunosuppressive properties; however, their effects on the human immune system remain poorly investigated. Here, we show that bortezomib, a proteasome inhibitor with anticancer activity, impairs several immune properties of human monocyte-derived dendritic cells (DCs). Namely, exposure of DCs to bortezomib reduces their phagocytic capacity, as shown by FITC-labeled dextran internalization and mannose-receptor CD206 down-regulation. DCs treated with
\end{abstract}

bortezomib show skewed phenotypic maturation in response to stimuli of bacterial (lipopolysaccharide [LPS]) and endogenous sources (including TNF- $\alpha$ and CD40L), as well as reduced cytokine production and immunostimulatory capacity. LPS-induced CCL-2/MCP-1 and CCL5/ RANTES secretions by DCs were prevented by $\mathrm{DC}$ treatment with bortezomib. Finally, CCR7 up-regulation in DCs exposed to LPS as well as migration toward CCL19/MIP-3 $\beta$ were strongly impaired. As a suitable mechanism for these effects, bortezomib was found to down-regulate
MyD88, an essential adaptor for TLR signaling, and to relieve LPS-induced activation of NF-kB, IRF-3, and IRF-8 and of the MAP kinase pathway. In summary, inhibition of DC function may represent a novel mechanism by which proteasome inhibitors exert immunomodulatory effects. These compounds could prove useful for tuning TLR signaling and for the treatment of inflammatory and immunemediated disorders. (Blood. 2006;108: 551-558)

(C) 2006 by The American Society of Hematology

\section{Introduction}

Pharmacologic inhibitors of the proteasome have recently received much attention in the light of their potent antitumor activity. ${ }^{1,2}$ In this setting, bortezomib (Velcade) was demonstrated to be effective in the treatment of multiple myeloma, when taken alone or in combination with traditional anticancer drugs. ${ }^{3,4}$ Besides, preliminary evidence indicates that also patients with non-Hodgkin lymphoma, acute leukemia, or some type of solid tumors may take advantage of treatment with this kind of drugs. ${ }^{5-9}$ The mechanism through which proteasome inhibitors prevent tumor growth is not completely understood even though inhibition of $\mathrm{NF}-\kappa \mathrm{B}$ was suggested to play a relevant role, especially in those malignancies in which this transcription factor is constitutively activated, such as multiple myeloma. ${ }^{1,2}$

Cumulating evidence indicating the importance of the ubiquitinproteasome pathway in different aspects of the immune response, including antigen processing, apoptosis, cell cycle, costimulation, adhesion, and chemotaxis, has fostered the evaluation of proteasome inhibitors as immunosuppressive agents. ${ }^{10}$ Evidence from the animal model indicates a potential role for proteasome inhibitors in the treatment of graft-versus-host disease. ${ }^{11-14}$ Similarly, these drugs proved useful in the animal model for the prevention of allograft rejection, arthritis, experimental autoimmune encephalomyelitis, and psoriasis. ${ }^{10,15-17}$ Whether proteasome inhibitors affect the immune function in humans remains controversial, since this kind of evaluation is hampered by the pre-existing immunodepres-

From the Department of Internal Medicine, University of Genoa, Italy; and the Department of Hematology, Oncology, and Immunology, University of Tübingen, Germany.

Submitted August 29, 2005; accepted March 3, 2006. Prepublished online as Blood First Edition Paper, March 14, 2006; DOI 10.1182/blood-2005-08-3494.

Supported by a grant from the Deutsche Forschungsgemeinschaft (SFB510) and by the University of Genoa (A.N. and A.B.). sion or by heavy pretreatment of the patients in the clinical studies carried out to date. However, lymphopenia was frequently detected in patients treated with bortezomib, ${ }^{4,6,18}$ which appears to be due to a direct inhibitory and proapoptotic effect of this compound in human lymphocytes ${ }^{11,14,19}$ (A.N., unpublished observations, October 2005).

A central role in the initiation of adaptive immune responses is played by dendritic cells (DCs), a trace leukocyte population with antigen-presenting cell (APC) function that patrols the peripheral tissues for the presence of unwanted antigenic material of infectious (and possibly tumoral) source. ${ }^{20,21}$ Alert signals such as pathogen-derived products are sensed by DCs through Toll-like receptors (TLRs) expressed at the cell surface and thereby trigger phenotypic and functional changes in DCs that lead to their migration to the afferent lymphoid organs. ${ }^{22,23}$ Here, DCs carry out their ultimate function by presenting the antigens captured in the periphery to $\mathrm{T}$ lymphocytes for the initiation of an antigen-specific response. ${ }^{20}$ TLR signaling in DCs on antigen encounter is believed to be critical for the subsequent immune outcome. ${ }^{23}$ Therefore, this is presently the subject of intense investigations which will possibly lead researchers to identify novel targeted immunomodulatory therapeutics. ${ }^{22}$

Given the potential of proteasome inhibitors to interfere with signaling pathways involved in APC function such as NF- $\mathrm{BB}, 1,2$ we have evaluated in the present study the effects of the proteasome

A.N. and K.S. contributed equally to this work.

Reprints: Peter Brossart, Department of Hematology, Oncology, and Immunology, University of Tübingen, Otfried-Müller-Strasse 10, D-72076 Tübingen, Germany; e-mail: peter.brossart@med.uni-tuebingen.de.

The publication costs of this article were defrayed in part by page charge payment. Therefore, and solely to indicate this fact, this article is hereby marked "advertisement" in accordance with 18 U.S.C. section 1734.

C 2006 by The American Society of Hematology 
inhibitor bortezomib on human monocyte-derived DCs. We show herein that this drug affects DC function at multiple levels by impeding antigen uptake through phagocytosis and by downmodulating DC response to the pathogen-derived product lipopolysaccharide (LPS), as well as to endogenous inflammatory cytokines and prostaglandins. ${ }^{20,22,24,25}$ LPS-induced signaling via $\mathrm{NF}-\kappa \mathrm{B}$, interferon regulatory factors (IRFs), and the mitogen-activated protein (MAP) kinase pathway were all found to be impaired by bortezomib in DCs, thus suggesting novel molecular targets of proteasome inhibitors in immune cells.

\section{Materials and methods}

\section{Reagents}

The medium used for cell cultures was RPMI 1640 supplemented with $10 \%$ inactivated FCS, $50 \mathrm{nM}$ 2-mercaptoethanol, and antibiotics, all purchased from Gibco-BRL (Grand Island, NY). Bortezomib (Velcade) was obtained from the pharmacy of the University Clinics in Tübingen (Tübingen, Germany). Human recombinant granulocyte-macrophage colony-stimulating factor (GM-CSF) (molgramostim, Leucomax) was from Novartis (Basel, Switzerland). Human recombinant interleukin-4 (IL-4), IL-1, IL-6, and TNF- $\alpha$ were purchased from R\&D Systems (Wiesbaden, Germany). CD40-ligand (CD40L) was from Bender Medsystems (Vienna, Austria). $\mathrm{PGE}_{2}$ was from Biomol (Plymouth Meeting, PA). LPS was obtained from Sigma (Steinheim, Germany).

\section{DC generation from adherent monocytes}

DCs were generated from adherent monocytes as described elsewhere. ${ }^{26-29}$ Buffy coat preparations from healthy volunteers were obtained from the blood bank of the University of Tübingen (Tübingen, Germany). Peripheral blood mononuclear cells (PBMCs) were isolated by Ficoll/Paque (Biochrom, Berlin, Germany) density gradient centrifugation. Cells were resuspended in serum-free X-VIVO 20 medium (Cambrex, Verviers, Belgium) and allowed to adhere $\left(1 \times 10^{7}\right.$ cells/well $)$ in 6 -well plates in a final volume of $2 \mathrm{~mL}$. After 2 hours of incubation at $37^{\circ} \mathrm{C}$, nonadherent cells were removed by extensive washing. DCs were generated by culturing the adherent monocytes in RPMI-based medium supplemented with 100 $\mathrm{ng} / \mathrm{mL}$ GM-CSF and $20 \mathrm{ng} / \mathrm{mL}$ IL-4. The medium was replenished with cytokines every other day. Cells were harvested for further experiments at day 6 of culture.

\section{Immunostaining and cell viability assay}

Cells were stained using fluorescein isothiocyanate (FITC)- or phycoerythrin-conjugated mouse monoclonal antibodies against CD14, CD25, CD69, CD80, HLA-DR, CD54, CD206 (Becton Dickinson, Heidelberg, Germany); CD40, CD86 (PharMingen, Hamburg, Germany); CD83 (Immunotech, Marseille, France); DC-SIGN and CCR7 (R\&D Systems, Minneapolis, MN), and mouse $\mathrm{IgG}$ isotype control (Becton Dickinson). Cells were analyzed on a FACSCalibur cytometer (Becton Dickinson). To calculate the percentage of positive cells, a proportion of $1 \%$ false-positive events was accepted in the negative control samples throughout.

For the determination of cell viability, cells were stained with $5 \mu \mathrm{g} / \mathrm{mL}$ propidium iodide (PI) and analyzed by flow cytometry.

\section{Mixed leukocyte reaction (MLR) assay}

A total of $10^{5}$ responding cells from allogeneic PBMCs were cultured in 96-well flat-bottom microplates (Nunc, Roskilde, Denmark) with $10^{4}$ stimulator cells. Thymidine incorporation was measured on day 5 by a 16-hour pulse with $\left[{ }^{3} \mathrm{H}\right]$ thymidine $(0.5 \mu \mathrm{Ci}[0.0185 \mathrm{MBq}] /$ well ; Amersham Life Science, Little Chalfont, United Kingdom). For the evaluation of the lymphocyte phenotype following culture with allogeneic DCs, $\mathrm{CD}^{+}$cells were isolated from total PBMCs, making use of CD3 MicroBeads from
Miltenyi (Bergisch Gladbach, Germany) according to the manufacturer's instructions. $\mathrm{CD}^{+}$PBMCs $\left(1 \times 10^{6}\right)$ per well were seeded in 24-well plates in the presence of $10^{6} \mathrm{DCs}$ of allogeneic source/well. Cells were harvested 48 hours later, washed with PBS, stained, and analyzed by flow cytometry by gating on the $\mathrm{CD}^{+}$lymphocyte population.

\section{Migration assay}

Cells $\left(2 \times 10^{5}\right)$ were seeded into a transwell chamber $(8 \mu \mathrm{m}$; BD Falcon, Heidelberg, Germany) in a 24-well plate, and migration to chemokine-CC motif-ligand 19 (CCL19/MIP-3ß; $100 \mu \mathrm{g} / \mathrm{mL}$; R\&D Systems, Wiesbaden, Germany) was analyzed after 16 hours by counting gated DCs for 60 seconds on a FACSCalibur cytometer. ${ }^{29}$

\section{Analysis of endocytic capacity}

For the analysis of endocytic activity, $1 \times 10^{5}$ cells were incubated with FITC-dextran (40 000 MW, molecular probes; Invitrogen, Karlsruhe, Germany) for 1 hour at $37^{\circ} \mathrm{C}$. As a control, $1 \times 10^{5}$ cells were precooled to $4^{\circ} \mathrm{C}$ prior to the incubation with dextran at $4^{\circ} \mathrm{C}$ for 1 hour. The cells were washed 4 times and immediately analyzed on a FACSCalibur cytometer. ${ }^{27}$

\section{Cytokine determination}

DCs were incubated at $1 \times 10^{6} /$ well in $2 \mathrm{~mL}$ medium and treated with different stimuli as indicated. Supernatants were collected and stored at $-70^{\circ} \mathrm{C}$ until use for cytokine determination. Cytokine concentrations were measured with commercially available 2-site sandwich enzyme-linked immunosorbent assays (ELISAs) from Beckman Coulter (Hamburg, Germany; IL-12 and TNF- $\alpha$ ) and R\&D Systems (Wiesbaden, Germany; CCL5/RANTES, CCL2/MCP-1), according to the manufacturers' instructions.

\section{Polyacrylamide gel electrophoresis (PAGE) and Western blotting}

Nuclear extracts were prepared from DCs as described previously. ${ }^{24,27}$ For the preparation of whole-cell lysates, cells were lysed in a buffer containing $1 \%$ Igepal, $0.5 \%$ sodium-deoxycholate, $0.1 \%$ SDS, 2 mM EDTA, $1 \mathrm{mM}$ PMSF, $2 \mu \mathrm{g} / \mathrm{mL}$ aprotinin, and $1 \mathrm{mM}$ sodium-orthovanadate. Protein concentrations of protein lysates were determined using a bicinchoninic acid (BCA) assay (Pierce, Perbio Science, Bonn, Germany). For the detection of nuclear localized NF- $\kappa \mathrm{B}$ family members, approximately $20 \mu \mathrm{g}$ nuclear extracts was separated on a $10 \%$ SDS-polyacrylamide gel and transferred onto nitrocellulose membrane (Schleicher \& Schuell, Dassel, Germany). Ponceau S staining of the membrane was performed to confirm that equal amounts of protein were present in every lane. The blot was probed with antibodies for RelB (C-19, rat polyclonal), IRF-3 (C-20, goat polyclonal), or IRF-8 (goat polyclonal), all from Santa Cruz Biotechnology (Santa Cruz, CA). The activation state of the MAP kinases p38 and ERK, as well as MyD88 levels, was determined by separating 20 to $30 \mu \mathrm{g}$ whole-cell lysates on a $12 \%$ SDS-polyacrylamide gel and subsequent transfer to nitrocellulose membranes. These were probed with antibodies specific for Phospho-p38 (Thr180/Tyr182, rabbit polyclonal), Phosphop44/42 (Thr202/Tyr204, mouse monoclonal), p38 MAP kinase (rabbit polyclonal; all from Cell Signaling Technology, New England Biolabs, Frankfurt, Germany), ERK1 (C-16, rabbit polyclonal; Santa Cruz Biotechnology) and MyD88 (N-19, goat polyclonal; Santa Cruz Biotechnology). ${ }^{29}$

\section{Reverse transcriptase-polymerase chain reaction (RT-PCR) for TLR4 expression}

Total RNA was isolated from cell lysates using QIAGEN RNeasy Mini anion-exchange spin columns (QIAGEN, Hilden, Germany) according to the instructions of the manufacturer. Total RNA $(1 \mu \mathrm{g})$ was subjected to a $20-\mu \mathrm{L}$ cDNA synthesis reaction using SuperScript RTII (Invitrogen, Karlsruhe, Germany). Oligo(dT) was used as primer. PCR amplification was performed using $2 \mu \mathrm{L}$ cDNA. Primers and PCR conditions for $\beta 2 \mathrm{~m}$ were described previously. ${ }^{25}$ Primer sequences for TLR4 were 


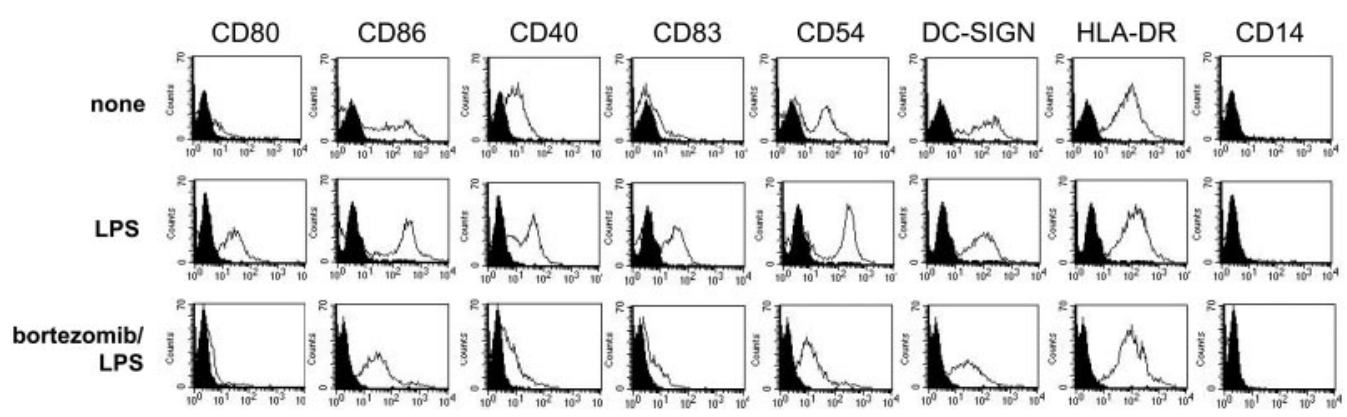

Figure 1. Effects of bortezomib on LPS-induced phenotypic changes in DCs. Adherent monocytes were cultured in the presence of GM-CSF and IL-4 for 6 days. Cells were then incubated in the presence or absence of $1 \mathrm{ng} / \mathrm{mL}$ bortezomib for 24 hours. LPS (100 ng/mL) was added during the last 16 hours where indicated in the figure. Afterward, cells were harvested, stained, and analyzed by flow cytometry. Matched isotype controls are presented as solid histograms.

5'-CTGCAATGGATCAAGGACCA-3' and 5'-TCCCACTCCAGGTAAGTGTT-3'. PCR temperature profiles were as follows: 5 minutes of pretreatment at $94^{\circ} \mathrm{C}$ and 22 cycles at $94^{\circ} \mathrm{C}$ for 30 seconds, annealing at $60^{\circ} \mathrm{C}$ for 30 seconds and $72^{\circ} \mathrm{C}$ for 30 seconds. RT-PCR reactions $(10 \mu \mathrm{L})$ were electrophoresed on a $3 \%$ agarose gel and stained with ethidium bromide for visualization under ultraviolet light.

\section{Statistical analysis}

Each experiment was performed at least 3 times with similar results. Representative experiments are shown. Unpaired $t$ tests were performed to evaluate the significance of the results.

\section{Results}

\section{Bortezomib prevents DC maturation in response to inflammatory signals}

In an attempt to evaluate whether the proteasome inhibitor bortezomib would affect DC immune properties, we found that exposure to pharmacologic concentrations of this compound ${ }^{8}$ did not modify the phenotype of DCs that were generated from peripheral blood monocytes by incubation with GM-CSF and IL-4 (data not shown). However, treatment with bortezomib inhibited the phenotypic changes that were induced by stimulation of DCs with LPS, a pathogen-derived signal that induces DC maturation and increases DC capacity to prime lymphocyte-mediated responses. ${ }^{20,21}$ Namely, DC pretreatment with the proteasome inhibitor prevented the up-regulation of the costimulatory molecules CD80, CD86, and CD40 (Figure 1). The levels of CD83, a surface marker expressed by mature $\mathrm{DCs},{ }^{21}$ were markedly reduced. Similarly, DCs exposed to bortezomib exhibited a down-regulation of the integrin CD54 and of DC-SIGN, a C-type lectin that mediates adhesion with $\mathrm{T}$ cells by stabilizing the DC/T-cell contact zone. $^{30}$ The normal up-regulation of HLA class 2 molecules in response to LPS was slightly reduced by the proteasome inhibitor while CD14 remained undetectable, thus ruling out de-differentiation to monocytes. DC maturation in response to the endogenous signals TNF- $\alpha$, CD40L, or a monocyte-conditioned medium mimics that includes IL-1, IL-6, PGE 2 , and TNF- $\alpha$ was also profoundly affected, as shown by the levels of CD1a and CD83 expression (Figure 2), indicating that bortezomib acts as a powerful inhibitor of DC function in response to a multiplicity of inflammatory stimuli (Figure 2).

Bortezomib has recently been proposed to affect lymphocyte viability. ${ }^{11,14,19}$ Therefore, we monitored herein DC survival on exposure to this proteasome inhibitor. We found that low bortezomib concentrations (up to $1 \mathrm{ng} / \mathrm{mL}$ ) that were able to modulate DC phenotype failed to affect DC viability (Figure $3 \mathrm{~A})$. However, exposure to higher concentrations of this compound reduced the yield of viable DCs, this effect being unaffected by the presence of maturation stimuli such as LPS or TNF- $\alpha$ (Figure 3B).

\section{Bortezomib blunts DC allostimulatory capacity and cytokine secretion}

The effect of bortezomib on DC immunostimulatory capacity was subsequently evaluated in MLRs. Here, we found that treatment of immature DCs with bortezomib does not substantially affect their capacity to prime allogeneic lymphocyte proliferation (Figure 4A). However, consistent with the effects of the proteasome inhibitor on the phenotypic response to LPS, we found that pretreatment with bortezomib reduced the capacity of LPS-primed DCs to induce proliferation (Figure 4B) and expression of activation markers (CD25, CD69, and HLA-DR) (Figure 4C) by allogeneic T cells.

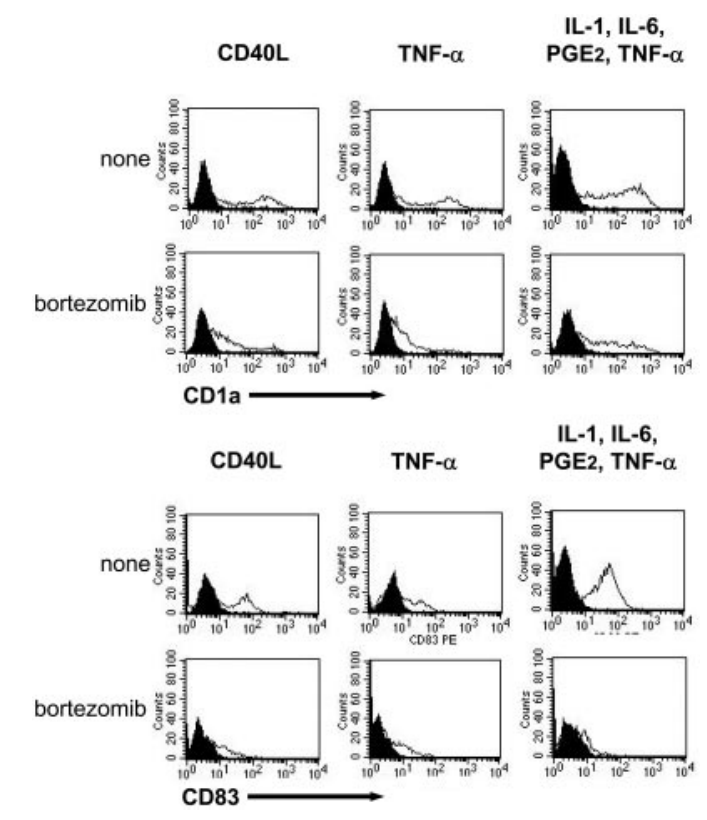

Figure 2. Bortezomib impairs DC response to endogenous inflammatory stimuli. DCs generated by culturing adherent monocytes in the presence of GM-CSF and IL-4 for 6 days were harvested and incubated for 24 hours with or without $1 \mathrm{ng} / \mathrm{mL}$ bortezomib. CD40L (100 ng/mL), TNF- $\alpha(20 \mathrm{ng} / \mathrm{mL})$, or the combination of IL-1 (2 ng/mL), IL-6 (100 ng/mL), PGE $2(1 \mu \mathrm{g} / \mathrm{mL})$, and TNF- $\alpha(20 \mathrm{ng} / \mathrm{mL})$ was added to the culture medium during the last 16 hours. Cells were subsequently harvested, washed, stained, and analyzed by flow cytometry. 
A

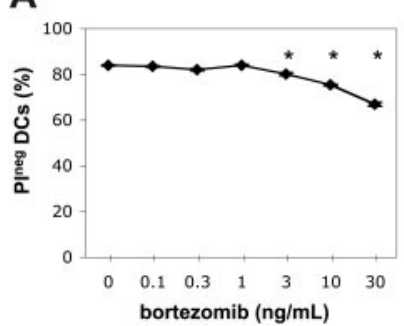

B

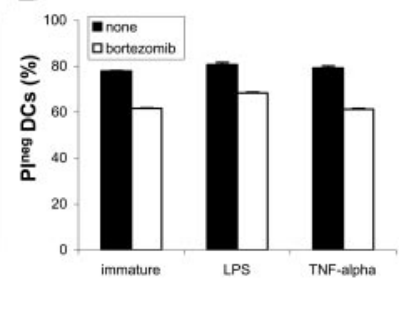

Figure 3. DC viability in response to treatment with bortezomib. (A) DCs generated from adherent monocytes by culture in the presence of GM-CSF and IL-4 were harvested at day 6 of culture and treated for 24 hours with the indicated concentrations of bortezomib. Thereafter, cells were harvested and stained with $5 \mu \mathrm{g} / \mathrm{mL} \mathrm{PI}$, and PIneg (viable) DCs were enumerated by flow cytometry. Means of triplicates with SDs are presented. ${ }^{\star} P<.05$ (B) Adherent monocyte-derived DCs were cultured in the presence of GM-CSF and IL-4 for 6 days. Thereafter, cells were stimulated for 24 hours with or without TNF- $\alpha(20 \mathrm{ng} / \mathrm{mL})$ or LPS $(200 \mathrm{ng} / \mathrm{mL})$ in the presence or absence of $5 \mathrm{ng} / \mathrm{mL}$ bortezomib. Cells were subsequently harvested, stained with $\mathrm{PI}$, and analyzed by flow cytometry. Results are shown as means of triplicates with SDs.

Besides the effect of bortezomib on the expression of costimulation molecules by DCs, it is likely that a reduced capacity to produce immunostimulatory cytokines is also responsible for this effect, because TNF- $\alpha$ and IL-12 secretion by DCs on stimulation with LPS were found to be profoundly reduced (Figure 5A-B).
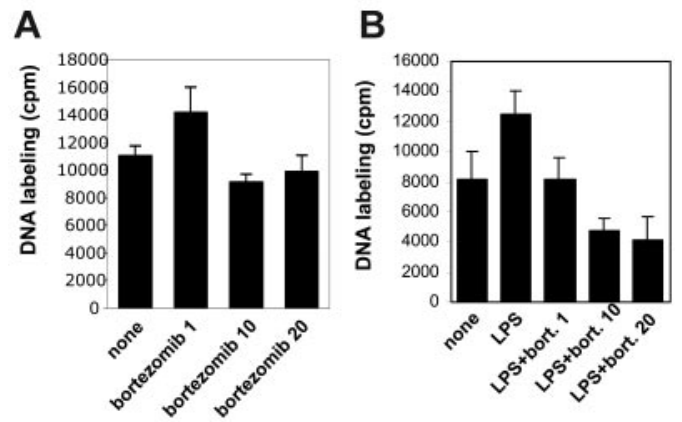

C

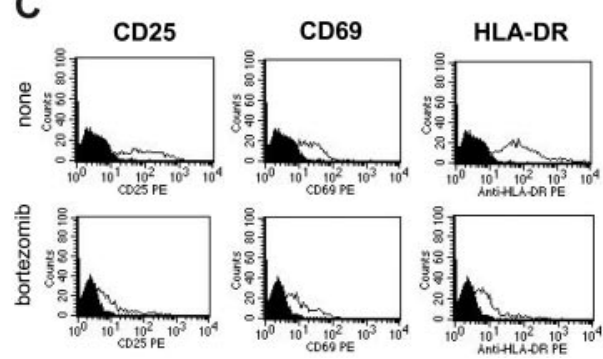

Figure 4. Effect of bortezomib on DC immunostimulatory capacity. (A) Adherent monocytes were incubated in GM-CSF and IL-4-containing medium. At day 6 of culture, cells were stimulated for 24 hours with bortezomib at the indicated concentrations. Thereafter, cells were harvested, washed, and used as stimulators in MLRs in the absence of bortezomib. Proliferation was measured at day 5 by thymidine incorporation. Results are presented as means of triplicates with SDs. (B) Adherent monocytes were incubated with GM-CSF and IL-4 to induce differentiation to DCs. At day 6 , cells were treated for 24 hours with bortezomib at the indicated concentrations (in $\mathrm{ng} / \mathrm{mL}$ ). LPS $(100 \mathrm{ng} / \mathrm{mL})$ was added during the last 16 hours of incubation. Cells were then harvested and used as stimulators in MLRs in the absence of bortezomib. Means of triplicates with SDs are presented. (C) DCs were generated from adherent monocytes by GM-CSF and IL-4. At day 6 of culture cells were incubated for 24 hours with or without $10 \mathrm{ng} / \mathrm{mL}$ bortezomib. LPS was added to the medium during the last 16 hours as a maturation stimulus. Thereafter, cells were harvested and washed, and $10^{6} \mathrm{DCs} /$ well were incubated for 48 hours in 24-well plates with $10^{6}$ allogeneic CD3 ${ }^{+}$PBMCs in the absence of bortezomib. Cells were then harvested and analyzed by flow cytometry by gating on the $\mathrm{CD}^{+}$lymphocyte population. Solid histograms represent the matched isotype controls.
A

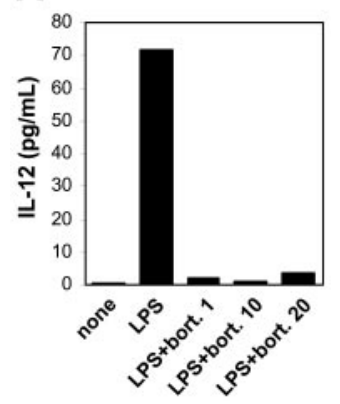

B

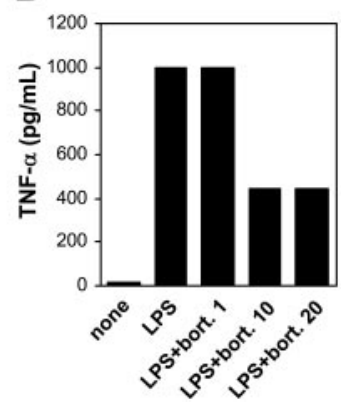

Figure 5. IL-12 and TNF- $\alpha$ secretion by DCs are modulated by bortezomib. (A-B) Adherent monocytes cultured in the presence of GM-CSF and IL-4 for 6 days were stimulated with or without bortezomib at the indicated concentrations (in $\mathrm{ng} / \mathrm{mL}$ ) for 24 hours. LPS $(100 \mathrm{ng} / \mathrm{mL})$ was added during the last 16 hours of incubation. Supernatants were subsequently collected, and IL-12 (A) and TNF- $\alpha$ (B) were determined by commercially available ELISAs.

\section{Impaired migratory capacity in DCs exposed to bortezomib}

Mature DCs typically acquire the capacity to migrate in response to CCL19/MIP-3 $\beta$ because of the expression of the cognate receptor CCR7. This effect is believed to be crucial to ensure that DCs reach the afferent lymphoid tissues. ${ }^{20,21}$ Here, we found that DCs exposed to bortezomib and thereafter stimulated with LPS lack capacity to migrate toward CCL19 (Figure 6A). In parallel, we observed that bortezomib blunted the expression of CCR7, the corresponding receptor for CCL19, on LPS-stimulated DCs, which likely accounts for the impaired migration ability (Figure 6B). Note that LPS-induced secretion of chemokine-CC motif-ligand 2 (CCL2/ MCP-1), a cytokine involved in monocyte recruitment to the sites of inflammation, ${ }^{31}$ and of chemokine-CC motif-ligand 5 (CCL5/ RANTES), a powerful chemoattractant and leukocyte activator, ${ }^{32}$ are also reduced when DCs are exposed to bortezomib (Table 1).

\section{Effects of bortezomib on DC intracellular signaling cascades}

The effect of the proteasome inhibitor bortezomib on intracellular signaling in DCs was subsequently evaluated, making use of LPS as a stimulus. It has become clear that LPS binding to TLR4

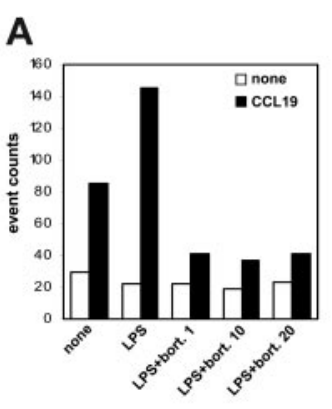

B

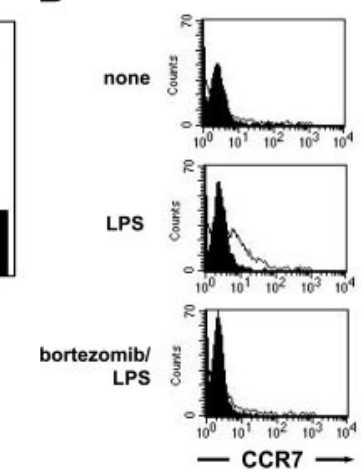

Figure 6. LPS-induced DC migration toward CCL19/MIP-3 $\beta$ is impaired by bortezomib. DCs were generated by incubating adherent monocytes with GM-CSF and IL-4. At day 6 of culture, cells were exposed for 24 hours to bortezomib at the indicated concentrations (in $\mathrm{ng} / \mathrm{mL}$ ). LPS (100 ng/mL) was added as a stimulus to the culture medium for the last 16 hours. DCs were then harvested and washed, and migration toward CCL19 was analyzed using transwell chambers. DCs $\left(2 \times 10^{5}\right)$ were seeded in the upper chamber in triplicates, and the number of migrated DCs was analyzed after 16 hours. (B) CCR7 expression was detected by flow cytometry on DCs generated from adherent monocytes as described in panel A. Cells were treated with or without bortezomib $(1 \mathrm{ng} / \mathrm{mL}$ ) for 24 hours and exposed to LPS (100 $\mathrm{ng} / \mathrm{mL}$ ) during the last 16 hours. 
Table 1. Effect of bortezomib on CCL2/MCP-1 and CCL5/RANTES secretion by DCs

\begin{tabular}{lrcccc}
\hline & None & LPS & $\begin{array}{c}\text { LPS }+ \\
\text { bortezomib } \\
\mathbf{1 ~} \mathbf{~ n g / m L}\end{array}$ & $\begin{array}{c}\text { LPS }+ \\
\text { bortezomib } \\
\mathbf{1 0 ~} \mathbf{~ n g / m L}\end{array}$ & $\begin{array}{c}\text { LPS }+ \\
\text { bortezomib } \\
\mathbf{2 0} \mathbf{~ n g / m L}\end{array}$ \\
\hline CCL2/MCP1 & 1063.9 & $>2000$ & 836.2 & 798.9 & 719.2 \\
CCL5/RANTES & 8.5 & $>2000$ & 422 & 50.2 & 42.3 \\
\hline
\end{tabular}

Adherent monocytes were cultured with GM-CSF and IL-4 for 6 days. Subsequently, cells were treated for 24 hours with bortezomib at the indicated concentrations. LPS was present in the culture medium during the last 16 hours. CCL2 and CCL5 secretions (in $\mathrm{pg} / \mathrm{mL}$ ) were determined in the supernatant using commercially available ELISAs.

induces a large number of genes through activation of NF- $\kappa$ B, MAP kinases, and IRFs. ${ }^{24,25,33}$ Proteasome inhibition affects NF- $\mathrm{B}$ signaling by preventing degradation of the NF- $\kappa \mathrm{B}$ inhibitor I $\mathrm{B} \alpha$, an effect that appears to account, at least partially, for the antitumor activity of proteasome inhibitors. ${ }^{1,2}$ We monitored herein LPSindued nuclear relocalization of RelB, a NF- $\mathrm{B}$ family member known to be relevant in DC differentiation and response to inflammatory stimuli. ${ }^{34,35}$ In fact, treatment with bortezomib led to reduced levels of this transcription factor in nuclear extracts after stimulation with LPS (Figure 7A). The MAP kinases pathway, which is involved in the regulation of DC maturation and survival, ${ }^{36-39}$ was also affected by bortezomib. In particular, we found here that DCs treated with bortezomib had reduced levels of phosphorylated p42/ERK2 protein on stimulation with LPS. Conversely, p38 phosphorylation was unaffected (Figure 7B). Finally, IRF-3 as well as IRF-8/ICSBP nuclear relocalizations were also impeded by bortezomib (Figure 7A), indicating that proteasome inhibition affects TLR4 signaling at multiple levels.

TLR intracellular signaling is mediated by adaptor proteins that are recruited to the TLR4-MD2 complex on ligand binding. ${ }^{22,33}$ Myeloid differentiation primary response gene 88 (MyD88) plays a key role because it specifically interacts with the IL-1 receptor-

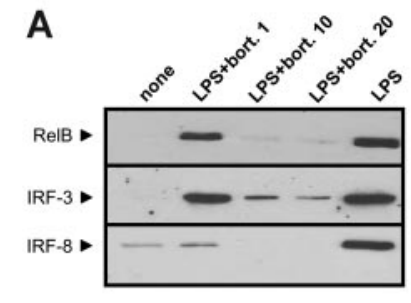

C

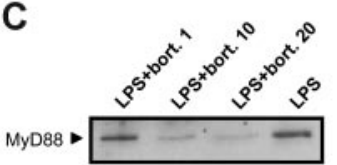

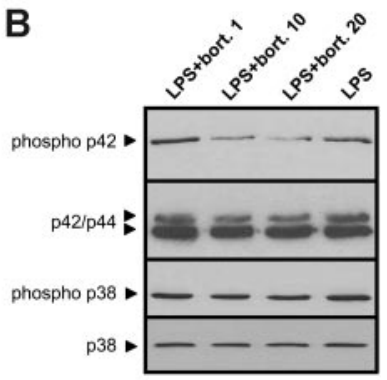

D

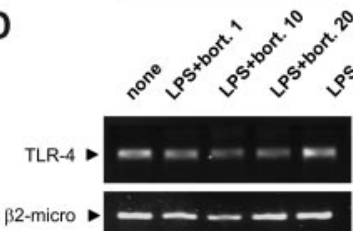

Figure 7. Bortezomib impairs TLR signaling cascades in DCs. Peripheral blood adherent monocytes were cultured with GM-CSF and IL-4 for 6 days. Subsequently, cells were incubated with the indicated concentrations of bortezomib (in $\mathrm{ng} / \mathrm{mL}$ ) for 8 hours before $100 \mathrm{ng} / \mathrm{mL}$ LPS was added to the culture medium. Sixteen hours later, cells were harvested and used for nuclear extracts $(A)$ or whole-cell lysate $(B-C)$ preparation. Nuclear-localized ReIB, IRF-3, and IRF-8 (A) and the phosphorylation state of ERK and p38 (B) as well as MyD88 levels (C) were detected by immunoblotting. Equal protein loading was confirmed by staining with ponceau S. (D) RNA was isolated from DCs that were obtained from adherent monocytes by culture with GM-CSF and IL-4 and thereafter stimulated with LPS with or without bortezomib as in panel A. Thereafter, cDNA was synthesized and used for semiquantitative PCR amplification of TLR4 and $\beta 2 \mathrm{~m}$ cDNA. associated kinases (IRAKs), IRAK1 and IRAK4, which in turn activate the MAP kinase cascade and NF-кB. Monitoring MyD88 levels in DCs that had been exposed to bortezomib demonstrated that the proteasome inhibitor blunts MyD88 expression (Figure 7C), an effect that may account for TLR signaling inhibition by bortezomib, at least with respect to NF- $\mathrm{BB}$ and MAP kinase relieving. Conversely, TLR4 levels in DCs were only found to be minimally affected by exposure to high concentrations of proteasome inhibitor (Figure 7D) as detected by semiquantitative RT-PCR.

\section{Reduced endocytic capacity in DCs treated with bortezomib}

To the completion of our observations on the effects of the proteasome inhibitor bortezomib on DCs, we monitored DC capacity to internalize FITC-labeled dextran as an assay of DC endocytic capacity. To this end, we decided to use immature DCs because these normally show pronounced internalization capacity as compared with mature DCs. ${ }^{20}$ Interestingly, pretreatment of DCs with bortezomib reduced their endocytosis ability (Figure 8), indicating that proteasome inhibition may affect DC function also by impeding antigen uptake for further processing and presentation. Subsequent analysis demonstrated how DC exposure to bortezomib prevents the expression of the mannose receptor CD206, which is likely to contribute to impair endocytosis in DCs (Figure 9A). ${ }^{40}$ Finally, bortezomib-induced CD206 down-regulation was also observed in DCs that were stimulated to undergo maturation in response to TNF- $\alpha$, LPS, CD40L, and a monocyteconditioned medium mimics (Figure 9B).

\section{Discussion}

The present study indicates the potential of proteasome inhibitors to interfere with DC function by down-modulating DC responsiveness to inflammatory signals and by reducing DC endocytic
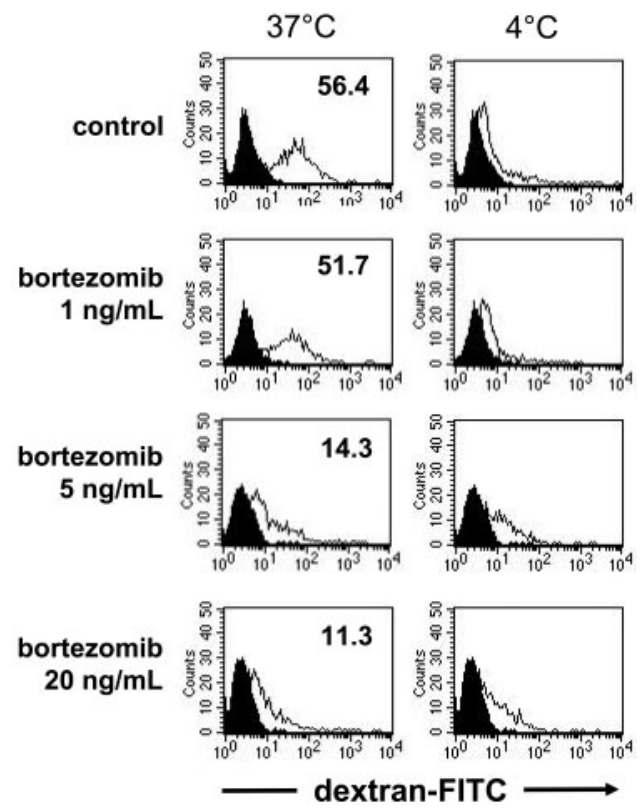

Figure 8. Treatment with bortezomib skews dextran uptake by DCs. (A) Adherent monocytes were incubated for 6 days in the presence of GM-CSF and IL-4. Cells were harvested and treated for 16 hours with bortezomib at the indicated concentrations. Thereafter, $2 \times 10^{5} \mathrm{DC}$ were incubated with FITC-dextran for 1 hour at $37^{\circ} \mathrm{C}$ or at $4^{\circ} \mathrm{C}$, washed 4 times, and analyzed by flow cytometry. Open histograms represent FITC-dextran-treated cells; solid histograms, cells incubated in the absence of FITC-dextran. Mean fluorescence intensity of DCs labeled with FITCdextran at $37^{\circ} \mathrm{C}$ is shown. 
A

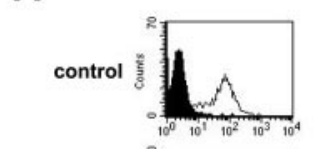

B
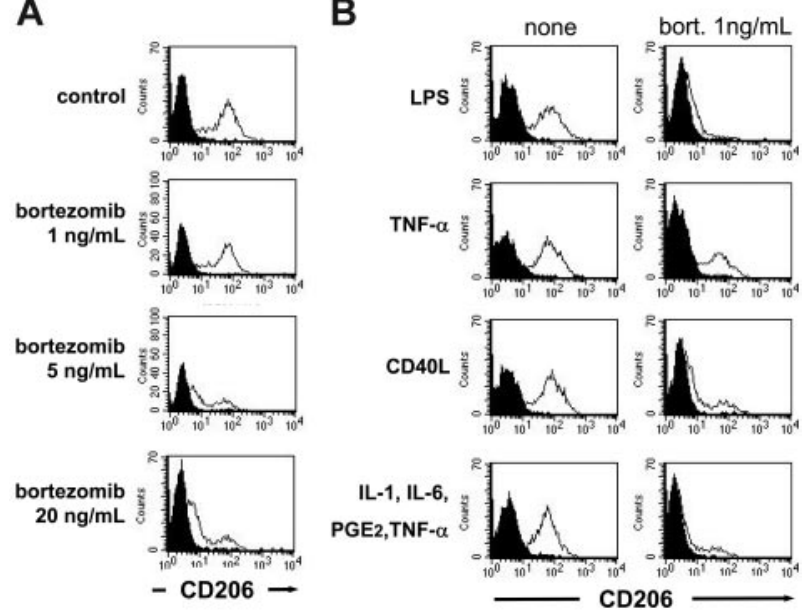

Figure 9. The mannose receptor CD206 is down-regulated in response to bortezomib. (A) DCs generated from adherent monocytes by a 6-day incubation in the presence of GM-CSF and IL-4 were stimulated for 24 hours with the indicated concentrations of bortezomib. Afterward, cells were washed, stained, and analyzed by flow cytometry. Solid histograms represent the matched isotype controls. (B) DCs generated from adherent monocytes by incubation with GM-CSF and IL-4 were exposed to $1 \mathrm{ng} / \mathrm{mL}$ bortezomib for 24 hours. LPS (100 ng/mL), TNF- $\alpha(20 \mathrm{ng} / \mathrm{mL})$, CD40L (100 ng/mL), or a cocktail of IL-1 (2 ng/mL), IL-6 (100 ng/mL), PGE 2 $(1 \mu \mathrm{g} / \mathrm{mL})$, and TNF- $\alpha(20 \mathrm{ng} / \mathrm{mL})$ was present in the culture medium during the last 16 hours of incubation. Thereafter, cells were harvested, stained, and analyzed by flow cytometry.

capacity. DC encounters with proinflammatory stimuli of exogenous (pathogen-derived products such as LPS) and endogenous (ie, TNF- $\alpha$, IL-1, prostaglandins) sources induce phenotypic and functional changes that enhance DC immunogenicity and regulate their life span..$^{20,21,41,42}$ Here, we found that, although not significantly affecting phenotype and immunostimulatory capacity of immature DCs, pharmacologic concentrations of bortezomib rather prevent phenotypic changes and activation that are induced in DCs by proinflammatory signals. ${ }^{8}$ Namely, treatment with the proteasome inhibitor affected the up-regulation of costimulation (CD40, CD80, CD86) and adhesion (CD54, DC-SIGN) molecules and DC markers (CD1a, CD83) in response to LPS, TNF- $\alpha$, CD40L, and a monocyte-conditioned medium mimics. Bortezomib inhibitory properties extended to DC capacity to secrete activatory cytokines such as IL-12 and TNF- $\alpha$ and to induce lymphocyte proliferation in MLRs. DCs that were exposed to bortezomib showed impaired migratory capacity toward CCL19/MIP-3 $\beta$ and reduced secretion of chemoattractants involved in inflammation and lymphocyte recruitment such as CCL2/MCP-1 and CCL5/RANTES. ${ }^{43}$ The latter results are consistent with those of a previous study that evaluated the effect of MG132 on retinal epithelial cells ${ }^{44}$ while diverging from those of another report in which no effect of proteasome inhibition on RANTES secretion was detected. ${ }^{45}$ Finally, we found that bortezomib also interferes with antigen capture by DCs because it reduced FITC-labeled dextran uptake and down-regulated the scavenger mannose receptor CD206. ${ }^{40}$

It should be observed that, although these effects appear to be merely functional in response to low bortezomib concentrations (up to $1 \mathrm{ng} / \mathrm{mL}$ ), high concentrations of proteasome inhibitor also affect DC viability, as detected in our experiments and consistent with recent data obtained with whole PBMCs. ${ }^{19}$ This effect appears to correlate with the up-regulation of proapoptotic Bcl-2 family members such as Bax in DCs exposed to bortezomib (A.N., unpublished data, March 2005; data not shown). Therefore, increased susceptibility to undergo apoptosis is likely to contribute to further down-regulate DC function in response to bortezomib, particularly when this compound is taken at high concentrations.

Following the observation that bortezomib affects DC maturation and viability, we evaluated potential effects of this proteasome inhibitor on intracellular signaling pathways that are known to regulate DC immune properties and survival..$^{20,21,28,29}$ To this end, we used LPS as a stimulus. Two major signaling pathways are normally triggered on TLR4 binding by LPS ${ }^{22,33}$ : one is dependent on Toll-IL-1 receptor (TIR) domain-containing adaptor protein (TIRAP) and MyD88. MyD88 recruits members of the IRAKs and tumor necrosis factor (TNF) receptor-associated factor 6 (TRAF6) to finally activate NF- $\kappa \mathrm{B}$ and the MAP kinase pathways. The other signaling pathway uses adaptor proteins such as TRIF-related adaptor molecule (TRAM) and TIR domain-containing adaptor inducing IFN- $\gamma$ (TRIF, also known as TICAM-1) to activate the IRFs (as well as NF- $\mathrm{B}$ ), thereby leading to production of type I IFN. NF-кB family members control DC development and different aspects of DC function, RelB being particularly relevant in this context. $20,21,34,35$ However, the IFN pathways are also being ascribed growing importance in DC biology. IRF-3 is a well-known mediator of IFN production by inflammatory cells and of endotoxic shock in response to LPS. ${ }^{46,47}$ IRF-8 is expressed in hematopoietic progenitors and is required for plasmocytoid DC development in mice. ${ }^{48-50}$ Interestingly, this molecule has also been related to the normal development and trafficking of Langerhans cells and dermal DCs, because it favors CCR6 and CCR7 expression. ${ }^{51}$ IRFs participate with NF- $\mathrm{kBs}$ in the control of IL-12 production. ${ }^{47,52-54}$ Thus, the current view suggests that IRFs and NF- $\kappa$ B signaling cooperate at multiple levels and are both necessary for inducing an optimal DC response to pathogens. Finally, MAPK kinases were also reported to be involved in modulating DC response to LPS. ${ }^{36-39}$

Here, we found that bortezomib blocks RelB activation on stimulation with LPS. NF-кB inhibition is a well-known effect of proteasome inhibitors and is attributed to the impeded degradation of the inhibitor $\mathrm{I} \kappa \mathrm{B} \alpha{ }^{1,2}$ Thus, this observation is consistent with previous studies. The MAPK pathway in DCs stimulated with LPS was also observed to be affected. Namely, although not preventing p38 activation, bortezomib reduced ERK phosphorylation. Such an effect was recently detected in studies with hematologic malignancies and suggests a selective effect of proteasome inhibition on the ERK pathway. ${ }^{55-57}$ Finally, we found that bortezomib interferes with IRF-3 and IRF-8 activation in response to LPS in DCs. Given the reported role for these IRFs in DC migratory capacity and IL-12 secretion, ${ }^{51-54}$ it is appealing to speculate a particular relevance for the obstruction of this signaling pathway in the inhibitory effects carried out by bortezomib.

We describe here for the first time that a proteasome inhibitor affects the expression of MyD88, an adaptor protein that plays a crucial role in upstream TLR signaling. ${ }^{22,33}$ The current model of LPS-induced signal cascades suggests that this effect may contribute to affect NF-кB and MAP kinase activation by IRAKs. On the contrary, the mechanism by which proteasome inhibition affects the IFN pathway, which is believed to be MyD88-independent, remains unclear. Even though $\mathrm{NF}-\kappa \mathrm{B}$ was proposed to play a role in IRF-3 transcriptional activity, ${ }^{58}$ it seems unlikely that the sole $\mathrm{NF}-\kappa \mathrm{B}$ relieving by bortezomib also accounts for inhibition of IRF-3 and IRF-8, based on the present understanding of IRFs signaling. ${ }^{22,33}$ Thus, more investigation is required to elucidate this effect. Yet, these data altogether delineate profound effects of bortezomib on key signal transduction cascades and suggest a 
common mechanism that may account for DC refractoriness to activation signals.

In conclusion, the present work shows that DC function is profoundly affected by bortezomib, probably via interference with $\mathrm{NF}-\kappa \mathrm{B}$ and other pivotal signal transduction pathways. To the extent to which the results of this study can be extrapolated to the in vivo setting, they suggest a novel mechanism of immunomodulation by proteasome inhibitors and foster the evaluation of these compounds as therapeutics capable of modulating TLR signaling and possibly inflammatory and immune responses.

\section{Acknowledgments}

We thank Sylvia Stephan and Bruni Schuster for the excellent technical assistance.

\section{References}

1. Adams J. The proteasome: a suitable antineoplastic target. Nat Rev Cancer. 2004;4:349-360.

2. Adams J. The development of proteasome inhibitors as anticancer drugs. Cancer Cell. 2004;5: 417-421.

3. Richardson PG, Barlogie B, Berenson J, et al. A phase 2 study of bortezomib in relapsed, refractory myeloma. N Engl J Med. 2003;348:26092617.

4. Orlowski RZ, Voorhees PM, Garcia RA, et al. Phase I trial of the proteasome inhibitor bortezomib and pegylated liposomal doxorubicin in patients with advanced hematologic malignancies. Blood. 2005;105:3058-3065.

5. Goy A, Younes A, McLaughlin P, et al. Phase II study of proteasome inhibitor bortezomib in relapsed or refractory B-cell non-Hodgkin's lymphoma. J Clin Oncol. 2005;23:667-675.

6. O'Connor OA, Wright J, Moskowitz C, et al. Phase II clinical experience with the novel proteasome inhibitor bortezomib in patients with indolent non-Hodgkin's lymphoma and mantle cell lymphoma. J Clin Oncol. 2005;23:676-684.

7. Cortes J, Thomas D, Koller C, et al. Phase I study of bortezomib in refractory or relapsed acute leukemias. Clin Cancer Res. 2004;10:3371-3376.

8. Papandreou CN, Daliani DD, Nix D, et al. Phase I trial of the proteasome inhibitor bortezomib in patients with advanced solid tumors with observations in androgen-independent prostate cancer. J Clin Oncol. 2004;22:2108-2121.

9. Kondagunta GV, Drucker B, Schwartz L, et al. Phase II trial of bortezomib for patients with advanced renal cell carcinoma. J Clin Oncol. 2004; 22:3720-3725.

10. Wu J. On the role of proteasomes in cell biology and proteasome inhibition as a novel frontier in the development of immunosuppressants. Am J Transplant. 2002;2:904-912.

11. Sun K, Welniak LA, Panoskaltsis-Mortari A, et al. Inhibition of acute graft-versus-host disease with retention of graft-versus-tumor effects by the proteasome inhibitor bortezomib. Proc Natl Acad Sci U S A. 2004;101:8120-8125.

12. Sun K, Wilkins DE, Anver MR, et al. Differential effects of proteasome inhibition by bortezomib on murine acute graft-versus-host disease (GVHD): delayed administration of bortezomib results in increased GVHD-dependent gastrointestinal toxicity. Blood. 2005;106:3293-3299.

13. Vodanovic-Jankovic $S$, Hari $P$, Jacobs $P$, Komorowski R, Drobyski WR. NF-kB as a target for the prevention of graft-versus-host disease: comparative efficacy of bortezomib and PS-1145. Blood. 2006; 107:827-834.

14. Blanco B, Perez-Simon JA, Sanchez-Abarca LI, et al. Bortezomib induces selective depletion of alloreactive T lymphocytes and decreases the production of Th1 cytokines. Blood. 2006;107: 3575-3583.

15. Luo H, Wu Y, Qi S, Wan X, Chen H, Wu J. A proteasome inhibitor effectively prevents mouse heart allograft rejection. Transplantation. 2001; 72:196-202.

16. Vanderlugt $C L$, Rahbe SM, Elliott PJ, Dal Canto $\mathrm{MC}$, Miller SD. Treatment of established relapsing experimental autoimmune encephalomyelitis with the proteasome inhibitor PS-519. J Autoimmun 2000;14:205-211.

17. Zollner TM, Podda M, Pien C, Elliott PJ, Kaufmann R, Boehncke WH. Proteasome inhibition reduces superantigen-mediated $T$ cell activation and the severity of psoriasis in a SCID-hu model. J Clin Invest. 2002;109:671-679.

18. Jagannath $\mathrm{S}$, Barlogie B, Berenson J, et al. A phase 2 study of two doses of bortezomib in relapsed or refractory myeloma. $\mathrm{Br} \mathrm{J}$ Haematol. 2004;127:165-172.

19. Chauhan D, Catley L, Li G, et al. A novel orally active proteasome inhibitor induces apoptosis in multiple myeloma cells with mechanisms distinct from Bortezomib. Cancer Cell. 2005;8:407-419.

20. Banchereau J, Briere F, Caux C, et al. Immunobiology of dendritic cells. Annu Rev Immunol. 2000; 18:767-811.

21. Reis e Sousa C. Activation of dendritic cells: translating innate into adaptive immunity. Curr Opin Immunol. 2004;16:21-25.

22. Beutler B. Inferences, questions and possibilities in Toll-like receptor signalling. Nature. 2004;430: 257-263.

23. Re F, Strominger JL. Heterogeneity of TLRinduced responses in dendritic cells: from innate to adaptive immunity. Immunobiology. 2004;209: 191-198.

24. Poltorak A, He X, Smirnova I, et al. Defective LPS signalling in $\mathrm{C} 3 \mathrm{H} / \mathrm{HeJ}$ and $\mathrm{C} 57 \mathrm{BL} / 10 \mathrm{ScCr}$ mice: mutations in TIr4 gene. Science. 1998;282:20852088.

25. Chow JC, Young DW, Golenbock DT, Christ WJ, Gusovsky F. Toll-like receptor-4 mediates lipopolysaccharide-induced signal transduction. J Biol Chem. 1999;274:10689-10692.

26. Nencioni A, Grunebach F, Zobywlaski A, Denzlinger C, Brugger W, Brossart P. Dendritic cell immunogenicity is regulated by peroxisome proliferator-activated receptor $\gamma$. J Immunol. 2002;169: 1228-1235.

27. Nencioni A, Lauber K, Grunebach F, et al. Cyclopentenone prostaglandins induce caspase activation and apoptosis in dendritic cells by a PPAR- $\gamma$ independent mechanism: regulation by inflammatory and T cell-derived stimuli. Exp Hematol. 2002;30:1020-1028.

28. Brossart P, Zobywalski A, Grunebach F, et al. Tumor necrosis factor $\alpha$ and CD40 ligand antagonize the inhibitory effects of interleukin 10 on T-cell stimulatory capacity of dendritic cells. Cancer Res. 2000;60:4485-4492.

29. Appel S, Mirakaj V, Bringmann A, Weck MM, Grunebach F, Brossart P. PPAR- $\gamma$ agonists inhibit toll-like receptor mediated activation of dendritic cells via the MAP kinase and NF-kB pathways. Blood. 2005;106:3888-3894.

30. Geijtenbeek TB, Torensma R, van Vliet SJ, et al. Identification of DC-SIGN, a novel dendritic cellspecific ICAM-3 receptor that supports primary immune responses. Cell. 2000;100:575-585.

31. Lu B, Rutledge BJ, Gu L, et al. Abnormalities in monocyte recruitment and cytokine expression in monocyte chemoattractant protein 1-deficient mice. J Exp Med. 1998;187:601-608.

32. Appay V, Rowland-Jones SL. RANTES: a versa- tile and controversial chemokine. Trends Immunol. 2001;22:83-87.

33. Miyake K. Innate recognition of lipopolysaccharide by Toll-like receptor 4-MD-2. Trends Microbiol. 2004;12:186-192.

34. Weih F, Carrasco D, Durham SK, et al. Multiorgan inflammation and hematopoietic abnormalities in mice with a targeted disruption of RelB, a member of the NF-кB/Rel family. Cell. 1995;80:331340.

35. Burkly L, Hession C, Ogata L, et al. Expression of relB is required for the development of thymic medulla and dendritic cells. Nature. 1995;373: 531-536.

36. Ardeshna KM, Pizzey AR, Devereux S, Khwaja A. The PI3 kinase, p38 SAP kinase, and NF-kB signal transduction pathways are involved in the survival and maturation of lipopolysaccharidestimulated human monocyte-derived dendritic cells. Blood. 2000;96:1039-1046.

37. Termeer C, Benedix F, Sleeman J, et al. Oligosaccharides of Hyaluronan activate dendritic cells via toll-like receptor 4. J Exp Med. 2002;195:99111.

38. Xia CQ, Kao KJ. Suppression of interleukin-12 production through endogenously secreted interleukin-10 in activated dendritic cells: involvement of activation of extracellular signal-regulated protein kinase. Scand J Immunol. 2003;58:23-32.

39. Franchi L, Condo I, Tomassini B, Nicolo C, Testi R. A caspaselike activity is triggered by LPS and is required for survival of human dendritic cells. Blood. 2003;102:2910-2915.

40. Boskovic J, Arnold JN, Stilion R, et al. Structural model for the mannose receptor family uncovered by electron microscopy of endo 180 and the mannose receptor. J Biol Chem. 2006;281:87808787.

41. De Smedt T, Pajak B, Klaus GG, et al. Antigenspecific $T$ lymphocytes regulate lipopolysaccharide-induced apoptosis of dendritic cells in vivo. J Immunol. 1998;161:4476-4479.

42. Rescigno M, Martino M, Sutherland CL, Gold MR, Ricciardi-Castagnoli P. Dendritic cell survival and maturation are regulated by different signalling pathways. J Exp Med. 1998;188:2175-2180.

43. Sallusto F, Mackay CR, Lanzavecchia A. The role of chemokine receptors in primary, effector, and memory immune responses. Annu Rev Immunol. 2000;18:593-620.

44. Wang XC, Jobin C, Allen JB, Roberts WL, Jaffe GJ. Suppression of NF-кB-dependent proinflammatory gene expression in human RPE cells by a proteasome inhibitor. Invest Ophthalmol Vis Sci. 1999;40:477-486.

45. Hidi R, Riches V, Al-Ali M, et al. Role of B7-CD28/ CTLA-4 costimulation and NF- $\mathrm{KB}$ in allergeninduced T cell chemotaxis by IL-16 and RANTES. J Immunol. 2000;164:412-418.

46. Weighardt $H$, Jusek $G$, Mages J, et al. Identification of a TLR4- and TRIF-dependent activation program of dendritic cells. Eur J Immunol. 2004; 34:558-564.

47. Sakaguchi S, Negishi H, Asagiri M, et al. Essential role of IRF-3 in lipopolysaccharide-induced interferon- $\beta$ gene expression and endotoxin 
From bloodjournal.hematologylibrary.org at UNIVERSITA STUDI DI GENOVA on April 5, 2012. For personal use

shock. Biochem Biophys Res Commun. 2003; 306:860-866

48. Schiavoni G, Mattei F, Sestili P, et al. ICSBP is essential for the development of mouse type I interferon-producing cells and for the generation and activation of CD8 $\alpha^{+}$dendritic cells. J Exp Med. 2002;196:1415-1422.

49. Tsujimura $\mathrm{H}$, Tamura $\mathrm{T}$, Ozato K. Cutting edge: IFN consensus sequence binding protein/IFN regulatory factor 8 drives the development of type I IFN-producing plasmacytoid dendritic cells. J Immunol. 2003;170:1131-1135.

50. Aliberti J, Schulz O, Pennington DJ, et al. Essential role for ICSBP in the in vivo development of murine CD $8 \alpha^{+}$dendritic cells. Blood. 2003;101: 305-310.

51. Schiavoni G, Mattei F, Borghi P, et al. ICSBP is critically involved in the normal development and trafficking of Langerhans cells and dermal dendritic cells. Blood. 2004;103:2221-2228.

52. Gautier G, Humbert M, Deauvieau F, et al. A type I interferon autocrine-paracrine loop is involved in Toll-like receptor-induced interleukin-12p70 secretion by dendritic cells. J Exp Med. 2005;201: 1435-1446.

53. Zhu C, Rao K, Xiong $\mathrm{H}$, et al. Activation of the murine interleukin-12 p40 promoter by functional interactions between NFAT and ICSBP. J Bio Chem. 2003;278:39372-39382.

54. Goriely S, Molle C, Nguyen M, et al. Interferon regulatory factor 3 is involved in Toll-like receptor 4 (TLR4)- and TLR3-induced IL-12p35 gene activation. Blood. 2006;107:1078-1084.

55. Yu C, Rahmani M, Dent P, Grant S. The hierarchical relationship between MAPK signalling and ROS generation in human leukemia cells undergoing apoptosis in response to the proteasome inhibitor Bortezomib. Exp Cell Res. 2004;295: 555-566.

56. Hideshima T, Chauhan D, Hayashi T, et al. Proteasome inhibitor PS-341 abrogates IL-6 triggered signalling cascades via caspasedependent downregulation of gp130 in multiple myeloma. Oncogene. 2003;22:8386-8393.

57. Yu C, Rahmani M, Conrad D, Subler M, Dent P, Grant S. The proteasome inhibitor bortezomib interacts synergistically with histone deacetylase inhibitors to induce apoptosis in $\mathrm{Bcr} / \mathrm{Abl}^{+}$cells sensitive and resistant to STI571. Blood. 2003; 102:3765-3774

58. Wathelet MG, Lin CH, Parekh BS, Ronco LV, Howley PM, Maniatis T. Virus infection induces the assembly of coordinately activated transcription factors on the IFN- $\beta$ enhancer in vivo. Mol Cell. 1998;1:507-518. 